\title{
How Prepared Is Africa for the COVID-19 Pandemic Response? The Case of Ethiopia
}

This article was published in the following Dove Press journal:

Risk Management and Healthcare Policy

\author{
Lemi Belay Tolu (iD) \\ Alex Ezeh ${ }^{2}$ \\ Garumma Tolu Feyissa $\mathbb{D}^{3}$ \\ 'Department of Obstetrics and \\ Gynecology, Saint Paul Hospital \\ Millennium Medical College, Addis Ababa, \\ Ethiopia; ${ }^{2}$ Dornsife School of Public \\ Health, Drexel University, Philadelphia, \\ PA, USA; ${ }^{3}$ Department of Health, \\ Behavior and Society, Jimma University, \\ Jimma, Ethiopia
}

\begin{abstract}
The coronavirus disease 2019 (COVID-19) is an ongoing pandemic caused by severe acute respiratory syndrome coronavirus 2 (SARS-CoV-2). The objective of this research communication is to describe the general epidemic preparedness of Ethiopia using "Ready score" criterion that was developed by PreventEpidemics.org. The ReadyScore criteria is used to determine whether a country is prepared to find, stop, and prevent epidemics. This set of criteria advises countries to take tailored measures based on their actual circumstances. Ethiopia's preparedness as assessed using the ReadyScore criteria is $52 \%$, which indicates that much work is expected from the country. Based on the current situation of Ethiopia's epidemic preparedness, the currently increasing trend in the number of COVID-19 cases and the current situation of Ethiopia in relation to its preparedness to mitigate the pandemic of Covid-19, we recommend (a) mass communication and community mobilization, (b) social distancing measures, (c) sanitary measures, (d) maximizing case tracing and detection, (e) developing detailed operational guidelines on preventive measures across different businesses, organizational and community settings, (f) measures for sustaining essential health services and ( $\mathrm{g}$ ) proactive measures to sustain life during the lockdown. Keywords: Covid-19, severe acute respiratory syndrome coronavirus 2, SARS-CoV-2, PANDEMICS, Africa, Ethiopia
\end{abstract}

\section{Introduction}

The coronavirus disease 2019 (COVID-19) is an ongoing pandemic caused by severe acute respiratory syndrome coronavirus 2 (SARS-CoV-2). ${ }^{1}$ The outbreak was first identified in Wuhan, Hubei Province, China, in December 2019. The World Health Organization (WHO) declared the outbreak to be a public health emergency of international concern on 30 January 2020 and recognized it as a pandemic on 11 March 2020..$^{2,3}$ As of May 21, 2020, more than 5,126,640 cases of COVID-19 have been reported in over 200 countries and territories, resulting in over 330,854 deaths. ${ }^{4}$ Ethiopia reported the first COVID-19 case on March 2020. ${ }^{5}$ As of May 21, 2020, Ethiopia has registered a total of 398 confirmed COVID-19 cases. $^{6}$

\section{How Prepared Is Ethiopia for Pandemic Response?}

Preventepidemics.org has created Ready Score to determine whether a country is prepared to find, stop, and prevent epidemics. ${ }^{7}$ Prevent Epidemics is a global website run by global experts and it provides a country-level data on epidemic preparedness. The ready score is a tool that was developed during the 2014 Ebola epidemics. The
Correspondence: Garumma Tolu Feyissa Email garummatolu@yahoo.com 
score uses the data from the WHO's Joint External Evaluation (JEE). It is based on 19 criteria to score the level of preparedness and response capacity. The scoring is made, first by a group of national experts of the country and then by an external group of international experts. ${ }^{8}$ The assessment is critical because it provides a snapshot of each country's capability to control outbreaks. The scoring criteria include points such as having adequate laboratory facilities to diagnose diseases, surveillance systems to detect when diseases spread, emergency response operations to effectively coordinate a response, and a trained workforce to implement control measures. The assessment shows gaps in these capacities and helps prioritize where to invest time and money to improve readiness.

\section{What Is the Level of Ethiopia's Preparedness for Epidemics?}

According to the ReadyScore, countries are classified into five levels:

1. Better prepared (over $\mathbf{8 0} \%$ ): This is an assessment level where a country has a robust system to find, stop and prevent health threats.

2. Work to do (40-80\%): This level of preparedness includes having some functioning systems in place to address an outbreak with some rooms for improvement. There is a potential for lives to be lost if a new health threat emerges in these countries.

3. Not ready (under $\mathbf{4 0 \%}$ ): If a country has assessed its ability to find, stop and prevent health threats and identified significant gaps, it will be categorized as not ready. Such countries are committed to improving epidemic preparedness, but an outbreak today could cause numerous deaths and spread to neighboring countries and the world.

4. In progress: This is the level of preparedness that is a characteristics of a country that has begun the external evaluation process, but does not have available data at the time and there is no robust way of knowing whether the country is prepared for an epidemic.

5. Unknown: Unknown category includes countries that have not volunteered to have an external, transparent evaluation of their ability to find, stop and prevent health threats.

According to the WHO JEE reports, Ethiopia scored 52\% ie, has work to do to prepare for the epidemic. The WHO JEE report stated that Ethiopia has committed to improve its preparedness, but an outbreak today could cause deaths and cross borders. The report appreciated Ethiopia's strength on immunization, national legislation, policy, and financing and identified the following gaps for improvement: emergence response operations, food safety, biosafety and biosecurity, national laboratory system and real-time surveillance. ${ }^{8}$

\section{Ethiopia's COVID-19 Response}

Since the pandemics of the COVID-19 were reported, Ethiopia started screening passengers at Bole international airport and used to send laboratory to South Africa for confirmation of suspected cases. Later, by the support of the WHO, Ethiopian Public Health Institute (EPHI) started laboratory test for COVID-19 on February 7, 2020. ${ }^{9}$ Along with capacitating the health system, the country dedicated one hospital (COVID-19), Eka Kotebe Hospital for isolation and treatment of Covid-19 cases. With further progress, treatment and testing facilities are being expanded to cities outside the main capital.

After reporting the first COVID-19 case on March 2020, Ethiopia exemplified what a whole-of-government response should look like in an emergency of this nature and magnitude. Prime Minister (PM) Abiy Ahmed promptly established a national Ministerial Council which ensured overall multisectoral coordination of the response including local fund mobilization efforts. In response to the call from the PM, government agencies and non-governmental organizations showed greater coordination than ever before.

Quarantining of passengers for 14 days, isolation, testing and contact tracing was actively conducted by repurposing different hotels and universities. The government called the residents to implement physical distancing, hand washing and cough hygiene. For physical distancing to be maximally implemented, Ethiopia closed all schools including universities, abandoned religious gatherings, regions launched staying at home and banned transport across cities. The laboratory test for COVID-19 which was initially started at EPHI only was decentralized to four regions to increase testing capacity of the country. ${ }^{10}$ The Information Network Security Agency (INSA) also designed information system to track the pandemic.

\section{What Measures Should Be Taken to Mitigate the Pandemic}

In addition to the measures taken so far, it would critical to follow the guideline prepared by Resolve to Save Lives 
gives guidance on when to loosen or tighten physical distancing measures according to levels of virus transmission, healthcare preparedness and public health capacity. ${ }^{11}$

When and How to Close due to COVID-19 Spread?

According to Resolve to Save Lives decision to tighten physical distancing depends on three domains of decision: level of viral transmission, health-care preparedness and public health capacity. Accordingly, strict mitigation measures are needed when one or more criteria in at least 2 of 3 domains are met (When to Tighten).

\section{The Current Situation of Ethiopia in Accordance to the Three Decision Domains}

\section{Ethiopia's COVID-19 Epidemiologic Situation (Viral Transmission)}

Ethiopia showed $19 \%$ growth in past 24-48 hours on April 11, 2020. While there has been great variation in daily increases, the number of cases is still increasing. As of April 14, 2020, there has been 82 cases reported. Despite being advocated by authorities and health officials, physical distancing was less implemented in major cities including Addis Ababa. This will increase the likelihood of exposure through mass gathering or congregation of people. Mass screening asymptomatic cases are not being carried out because of the limited capacity and the likelihood of delayed detection of cases is high. According to EPHI report currently, about 20 contacts have been identified for each confirmed cases, with this about one-third of the population would be infected at the peak and the outbreak will have protracted trajectory, where the infection peaks two months from now. From the domain of prevention strategy, reducing contacts by $50 \%$ through enforcing physical distancing averts 15 million infections that would have occurred at the peak at the national level. Based on the assumption by EPHI, at the peak of the outbreak, about $60 \%$ of the population would be exposed to the virus. By the end of May, 1.94 million people would be infected with the virus and the outbreak will reach to peak on day 110 (in July) infecting likely 33, 697,791 people. If the physical distancing continues to be implemented properly, 15442351 of the infections that could have occurred at the peak would be averted.

\section{Ethiopia's COVID-19 Health-Care Preparedness}

Though different preparation and repurposing activities are undergoing, Ethiopia has limited health-care capacity especially of Intensive Care Unit (ICU). Ministry of
Health $(\mathrm{MOH})$ recently disclosed to media that Ethiopia has totally 450 mechanical ventilators in both private and government settings. Currently, the number of Covid-19 cases is increasing daily. There are more admissions and less discharges. Additionally, Ethiopia has limited personal protective equipment and health professionals are complaining about it from the start of the pandemic.

\section{Ethiopia's COVID-19 Public Health Capacity}

Though repurposing different hotels and universities is being done, Ethiopia is having congested mandatory quarantine because of continued flying airlines, especially more cases coming from Dubai. Given the longstanding social bond in the community, it is not easy to fully implement physical distancing recommendations. In addition, it will not be an easy task for the majority who live on daily labor in this era of quarantine since the government does not have capacity to provide life-sustaining supplies or cash to each. Moreover, there is a shortage of sanitation supplies, such as hand sanitizer to place at entry of buildings including workplaces.

\section{What Should Be the Next Immediate Pandemic Adaptive Response for Ethiopia?}

Depending on what we presented above, the current Ethiopia's situation and evidence on the three decision domains, we recommend strict mitigation measures to be practiced. Hence, we recommend that Ethiopian government to tighten the following actions urgently (marshaling all resources to mitigate transmission of virus):

(a) Mass communication and community mobilization: Clear, honest and transparent aggressive mass communication tailored to the realities of local populations through various platforms, including traditional media (print, mainstream TV and radio) and new methods organized remotely through social media, telegrams, WhatsApp and other virtual platforms. In addition, there should be community mobilization activities to build resilience in the community in withstanding the social, psychological, physical, social impact of the pandemic. In addition, mobilizing civil societies and private sectors would be essential to pool the necessary resources and get all the necessary measures into place with minimized negative consequences. 


\section{(b) Social distancing measures:}

- Tight mandatory quarantine of flight arrivals and contacts of cases for 14 days.

- Strengthen regulations that sick people should not go out.

- Recommend mandatory face mask if sick persons are to go out for mandatory purposes.

- Ban visits to nursing homes, hospitals, and congregate facilities.

- Avoid any crowding and tighten strict physical distancing to 6 feet.

- Tighten the already ongoing closure of daycare, schools, and Universities.

- Ban all gatherings including religious (above 10, 50 people if physical distance of 6 feet met)

- Close all bars, night clubs and restaurant (open only delivery/to go).

- Educate bars, restaurants, and cafeterias to provide alternative service delivery strategies, such as telephone-based service, home delivery or take out services with strict precautions.

- Avoid large crowds during the purchase of food items by enforcing the sale and delivery of these items locally close to households. Moreover, consideration of home delivery options is important.

- Facilitating mobile and online related payments and where possible home delivery of items to reduce the possibility of gathering and physical contacts.

- Close non-essential businesses (establish a category for essential and non-essential business).

- Partial or complete special situation business closures depending on evolving knowledge (eg, infectivity of children), availability of PPE, testing and treatment materials locally, community burden, acceptance, and adherence of physical distancing. Special business situations include strategically important entities (eg, infrastructure), entities that can reopen while ensuring safe physical distancing, exclusion of anyone sick, and mandatory handwashing/sanitizing at entry and periodically during day.

(c) Sanitary measures: Tighten the already started handwashing, cover cough and surface and object cleaning. Public education to frequently sanitize articles, door entrances and clothing items at home and in lifesustaining business areas (restaurants, fruits, and vegetable vendors). (d) Maximizing case tracing and detection: It is becoming undeniable that the social distancing has not been fully implemented across the country. Hence, it is critical that the country maximizes the testing capacity for effective case tracing and detection.

(e) Developing detailed operational guidelines on preventive measures across different business, organizational and community settings: It is encouraging to see that the Ministry of Health (MOH) of Ethiopia released the national comprehensive COVID-19 management handbook for Ethiopia on April 13, 2020. However, this guideline needs to be further operationalized and further details should be provided based on the country's local circumstances instead of leaving it open for the readers. Especially, health institutions at different level should develop additional operational guidelines, including infection prevention guidelines to prevent nosocomial transmission of the virus. Moreover, local authorities and officials of different sectors should develop locally tailored operational guidelines.

(f) Measures for sustaining essential health services: Experience in past epidemics has shown that lack of access to essential health services and shut down of services unrelated to the epidemic response resulted in more deaths than the epidemic itself. The government should identify essential health services (antenatal and postnatal care, labor and delivery, reproductive health services, acute abdomen, trauma, under five children care ... etc.) and other health services (chronic medical conditions). Government should give priority and facilitate access to essential health services. The government should make sure that pharmacy, clinics, and hospitals remain open during the pandemic crisis and continue to provide service with no additional cost.

- Expand telemedicine and house-to-house essential health services for chronic and ambulatory services. Hospitals should collaborate with Ethio-telecom (the only network provider in Ethiopia) to provide hot lines and phone consultations to patients with chronic conditions.

- Volunteers (community health workers, students, and others) may be provided short-term training to provide some essential health services in the community.

- Ensure that transportation facilities are ready for seeking emergency health services. Existing 
transportation facilities may be repurposed and used to transport patients.

(g) Proactive measures to sustain life during the lockdown: As many people in Ethiopia depend on daily activity to secure food, strict mitigation might cause hunger and starvation. This might result in double catastrophe of virus itself and food insecurity and hunger. To prevent this calamity, the government, non-governmental organizations, and civil societies should intensify public education about safe water and food storage. There should be maximal collaboration of public institutions with private sectors. The community should be mobilized so that there will strong resilience, self-help, and cooperation among community (marshaling a whole of a society) to support each other. Especially, it is essential to support the poor and vulnerable by shifting available resources and mobilizing additional resources from private sectors and work strategically to secure essential food stocks for 6-12 weeks, when normal supplies of food may be disrupted. Given enough determination on the part of the authorities, repurposing and redeploying existing mechanisms and assets (such as health and agricultural extension programs, safety net schemes, early warning systems, town halls, universities, churches and mosques) can be quickly done. The authorities should also make sure that there is no unnecessary increment of food prices. Where possible subsidies and mobilization of community resources should help in ensuring that the poor are continuously being fed.

\section{When and How to Reopen After COVID-I 9}

According to Resolve to Save Lives COVID-19 physical distancing measures can be loosened when all the criteria under three domains of decision: level of viral transmission, health-care preparedness and public health capacity are met. Hence, we recommend Ethiopia to strategically decide when and how to reopen according to When and How to Loosen.

In conclusion, Ethiopia should act based on the objective assessment addressing the health system preparedness, the public preventive measures, and the ongoing spread of the infection. Detailed operational guidelines should be developed at each level of the government administration in each sector. Strict implementation measures should be taken to get the mitigation guidelines implemented.

\section{Disclosure}

The authors declare no conflict of interest.

\section{References}

1. Adhikari SP, Meng S, Wu Y-J, et al. Epidemiology, causes, clinical manifestation and diagnosis, prevention and control of coronavirus disease (COVID-19) during the early outbreak period: a scoping review. Infect Dis Poverty. 2020;9(1):1-12. doi:10.1186/s40249020-00646-x

2. World Health Organization statement on the second meeting of the International Health Regulations. Emergency Committee regarding the outbreak of novel coronavirus (2019-nCoV). 2005. Available from: https://www.who.int/news-room/detail/30-01-2020-statementon-the-second-meeting-of-the-international-health-regulations(2005)-emergency-committee-regarding-the-outbreak-of-novel-coro navirus-(2019-ncov). Accessed January 30, 2020.

3. World Health Organization. WHO Director-General's Opening Remarks at the Media Briefing on COVID-19-11 March 2020. Geneva, Switzerland. Available from:: https://www.who.int/dg/ speeches/detail/who-director-general-s-opening-remarks-at-the-mission -briefing-on-covid-19-13-march-2020. Accessed June 10, 2020.

4. COVID, Coronavirus global cases by the Center for Systems Science and Engineering (CSSE) at Johns Hopkins University (JHU). Available from: https://coronavirus.jhu.edu/map.html. Accessed June 10, 2020

5. Ethiopia Confirmed The First Case of COVID-19 | FMOH \%U. Available from: http://www.moh.gov.et/ejcc/en/node/194. Accessed June 10, 2020.

6. Coronavirus Update (Live)- Worldometer,Ethiopia \%U. Available from: https://www.worldometers.info/coronavirus. Accessed June 10, 2020.

7. Lives RtS. Resolve to Save Lives: readyScore \%U. Available from: https://resolvetosavelives.org/prevent-epidemics/readyscore. Accessed June 10, 2020.

8. World Health Organization. Joint External Evaluation of IHR Core Capacities of the Federal Democratic Republic of Ethiopia: Mission Report. World Health Organization; 2016. Available from: https:// www.who.int/ihr/publications/WHO-HSE-GCR-2016.24/en/. Accessed June 10, 2020.

9. WHO | Regional Office for Africa; Scaling up coronavirus outbreak readiness in Ethiopia \%U. Available from: https://www.afro.who.int/ photo-story/scaling-coronavirus-outbreak-readiness-ethiopia. Accessed June 10, 2020.

10. AfricaNews, Coronavirus - Ethiopia: Notification on Situational COVID 19 Update \%U. Available from: https://www.africanews.com/ 2020/04/04/coronavirus-ethiopia-notification-on-situational-covid-19update.Africanews2020. Accessed June 10, 2020.

11. Adaptive Response \%U. Available from: https://preventepidemics.org/ coronavirus/insights/adaptive-response.PreventEpidemics. Accessed June 10, 2020. 


\section{Publish your work in this journal}

Risk Management and Healthcare Policy is an international, peerreviewed, open access journal focusing on all aspects of public health, policy, and preventative measures to promote good health and improve morbidity and mortality in the population. The journal welcomes submitted papers covering original research, basic science, clinical \& epidemiological studies, reviews and evaluations, guidelines, expert opinion and commentary, case reports and extended reports. The manuscript management system is completely online and includes a very quick and fair peer-review system, which is all easy to use. Visit http://www.dovepress.com/testimonials.php to read real quotes from published authors.

Submit your manuscript here: https://www.dovepress.com/risk-management-and-healthcare-policy-journal 